\title{
GOOD NEWS AND BAD
}

\section{Public perceptions of crime, corruption and government}

Robert Mattes, ${ }^{1}$ Centre for Social Science Research

University of Cape Town

Rmattes@commerce.uct.ac.za

\begin{abstract}
Idasa and Afrobarometer public opinion surveys conducted since 1994 reveal that levels of reported experiences with crime are unchanged over the past four years, but that public perceptions of overall safety and the performance of the police are actually improving. Of greatest concern is that the January-February 2006 survey found that almost half of all South Africans think that "all" or "most" police officials are involved in corruption. These are the highest rates recorded across ten different types of public servants. In contrast to the improving trends in public perceptions of crime, citizen views of corruption in the police (and other government institutions) are becoming worse.
\end{abstract}

$\mathrm{O}$ fficial police statistics attempt to provide an objective picture of the extent of crime. But public opinion surveys can provide an important complement to official statistics by assessing people's reported experiences with both crime and the police, as well as their subjective (in)security and evaluations of the police and government attempts to reduce crime. And if regularly repeated, these 'snapshot' surveys can create a 'moving picture' of critical trends.

A review of Idasa and Afrobarometer surveys conducted in South Africa since 1994 reveals several such trends. In contrast to what might be inferred from the noise of partisan debate and expert commentary, these trends show that levels of reported experiences with crime are unchanged over the past six years, though at exponentially higher levels than what is reported to the police and thus included in the official crime statistics.

Furthermore, public perceptions of overall safety and the performance of the police are actually improving, albeit from a fairly dismal base. At the same time, these surveys also demonstrate that almost half of all citizens think that most police officials are involved in corruption, most find it difficult to get help from the police and some even have to pay bribes to get this help.

Do personal experiences match the official view? Given the heat regularly generated by news media coverage of crime, and opposition parties' critiques of government performance in reducing crime, the first question to ask is whether ordinary South Africans share these concerns. Since 1994 Idasa and Afrobarometer surveys have asked South Africans: "W hat are the most important problems facing this country that the government ought to address?", to which respondents can provide up to three answers.

The results confirm that in the aftermath of South Africa's successful though turbulent transition to democracy in 1994, crime quickly became one of people's most prominent concerns, replacing their 
fears of political violence. Between 1997 and 2000, six in every ten South Africans rated crime or some related aspect as one of the most important problems that government should address, consistently ranking behind only job creation as the most prominent issue (Figure 1).

Since reaching their highest point ever in the run-up to the 1999 election, however, levels of public emphasis on crime - relative to other concerns have actually plummeted, falling by one half from $65 \%$ to $23 \%$ in 2006 . Moreover, crime has lost its long held position as the nation's 'number two' problem and now ranks behind housing $(28 \%)$ in a statistical third place along with poverty at $27 \%$, and HIV/AIDS (25\%).

$O$ ver the years, government has fended off questions about these public concerns, often chalking them up as the whingeing of previously protected white communities now exposed to the same realities long endured by black South Africans. The data, however, paint a far more complex reality. It is true that blacks' rating of crime as a priority has consistently lagged considerably behind those of white (but also of Coloured and Indian) respondents. Yet, at the height of public anxiety about crime, as many as $55 \%$ of black respondents listed crime as a priority problem (Figure 2).

Indeed, South Africans of all race groups have consistently placed the same four or five issues at the top of what might be called the 'public agenda, though they have often ordered them quite differently. This is still the case. Crime is one of the five most cited problems by all groups in 2006, but although it is rated as the second most prominent problem by whites $(48 \%)$, it is only the fifth most frequently mentioned priority by black Africans $(17 \%)$.

Part of this decline is simply a function of the emergence of other problems competing for public attention, like HIV/AIDS, which was first mentioned by respondents in 1997, and cited by almost one in three $(30 \%)$ by 2004 . Yet part of it is also undoubtedly a reflection of an actual decline in crime over this period.

Indeed, South Africans appear to agree that the country is at least somewhat safer than it was a few

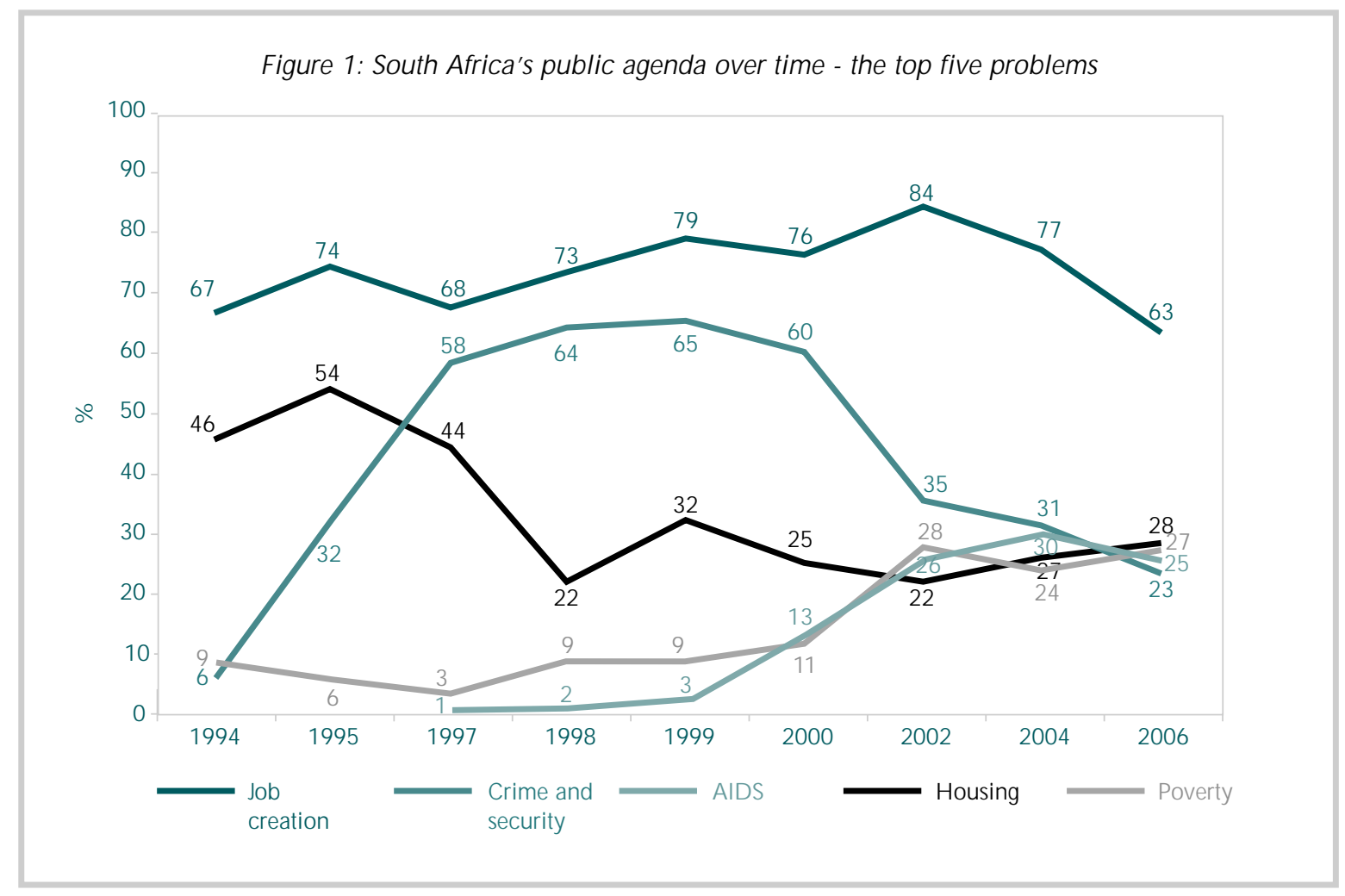




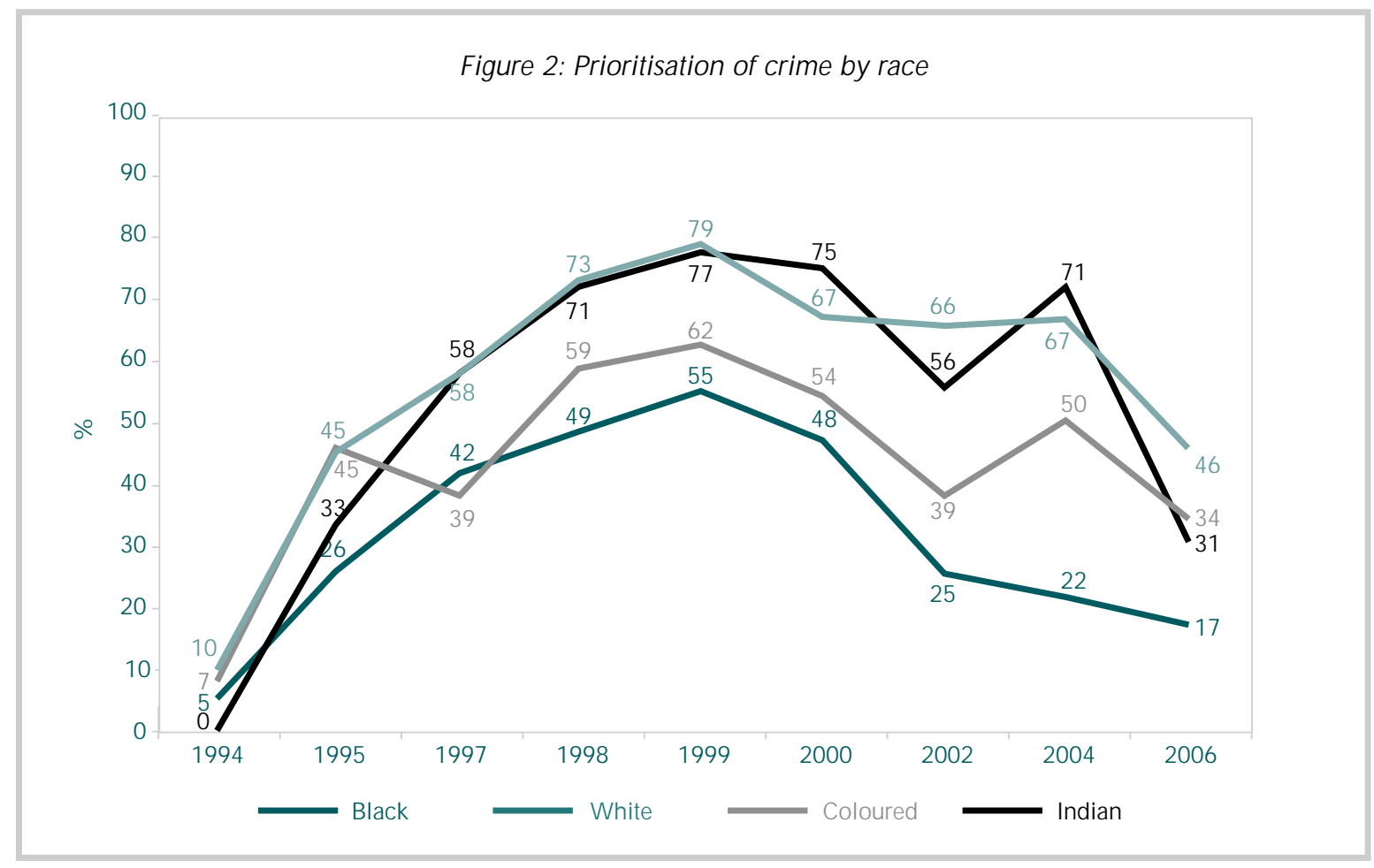

years ago. They are less likely today to report that they or their family felt insecure in their home in the last 12 months than they were in 2000 (51\% as opposed to $61 \%$ ) (Figure 3). They are also more likely, by a factor of two, to say that safety from crime is better now than "a few years ago" than they were in 2000 (Figure 4).

At the same time, the proportion of respondents who said that they, or someone in their family, had something stolen from their house or were the victim of a physical attack in the previous 12 months has remained constant (at least since this question was first asked in 2002) (Figure 3).

These partial successes appear to be yielding more positive views of government efforts to fight crime. As of January-February 2006, just over one third (36\%) of all South Africans felt the government was handling crime "fairly" or "very well" (Figure 4). This was the third low est rating across 14 different performance areas tapped by the survey (beating only reducing inequality and creating jobs), and also represented a five percentage point reduction since 2004.

Still, public evaluations are significantly more positive now than six years ago when just $18 \%$ approved of
Figure 3: Insecurity and personal experience of crime

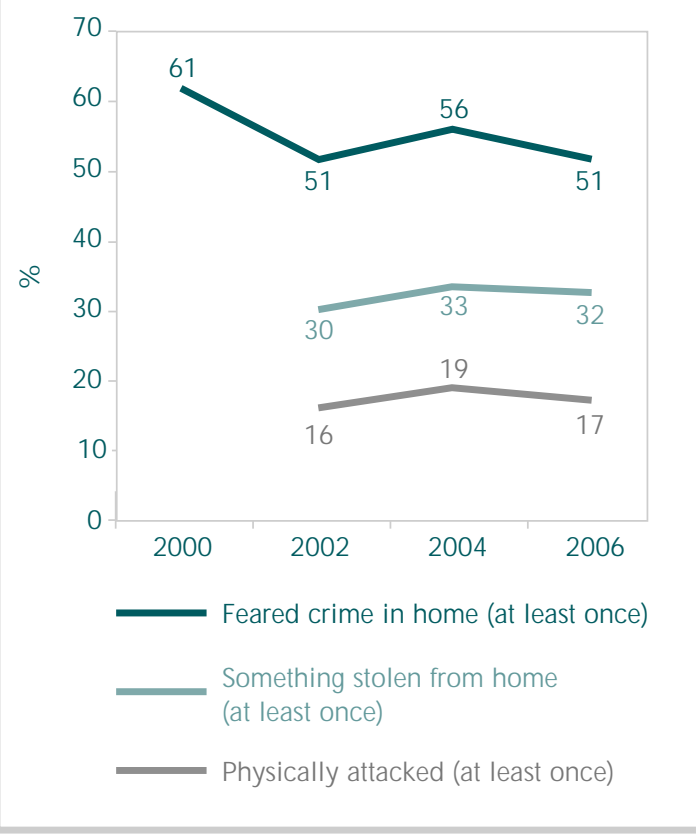

government performance on crime. This upward trend mirrors the one described above, namely that people have the sense that safety from crime is better than a few years ago. 
Figure 4: Evaluations of police performance and improvements in safety

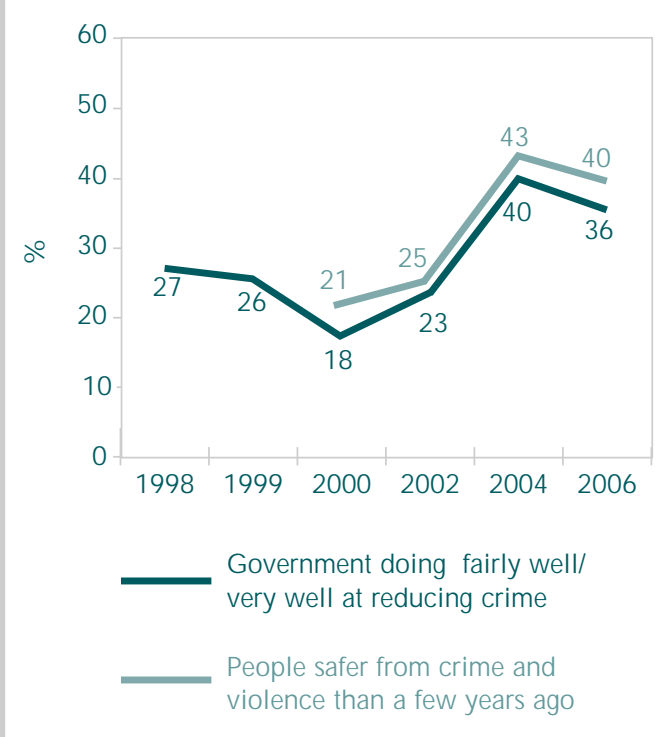

The results also strongly suggest that actual levels of crime are far higher than what is reflected in the official police record. To be sure, the survey questions were not designed to measure the crime rate in any precise fashion, but rather to identify those respondents who had experienced crime directly or indirectly, and then to gauge the impact of these experiences on other attitudes. But even after taking into account the obviously blunt nature of the question, as well as the complications added by asking about "you, or anyone in your family," the data indicate that, at best, a minority of crimes like burglary and assault are actually reported to the police.

Take for instance the $19 \%$ of respondents in the 2004 survey who said that they or someone in their family had been physically attacked. In terms of how crime statistics are calculated, this would yield a rate of approximately 13,000 assaults per 100,000 population. ${ }^{2}$ Even after adding together the data on all reported assaults, rape, and attempted murders included in the 2003/04 official crime statistics, the figure was only 739 per 100,000 .

Also consistent with the trends in improving perceptions of safety is the steadily improving overall image of the police. In early 2006 , just fewer than one half of the public $(48 \%)$ said they trusted the SAPS, up substantially from the 35\% who did so in 2000 . But at least two important caveats are in order here:

- Trust in all of the country's political and state institutions has been following an upward trend since 2000, a trend that closely follows the steadily upward trajectory in South Africans' confidence in the national economy over this same time period.

- Regardless of the trend, the police are still seen as one of the least trustworthy institutions in the country, ahead only of local councils and opposition parties (Figure 5). And the far higher levels of trust in the $\mathrm{N}$ ational $\mathrm{D}$ irectorate of Public Prosecutions (62\%) are a real eye-opener, given the recent controversies over the structural relationships of the NDPP and the SAPS (see P Mashele in SA Crime Q uarterly No 17, September 2006).

\section{Why is the SAPS viewed in such a bad light?}

Besides the continued, though decreasing, public dissatisfaction with the level of crime in the country, one important reason behind the SAPS's poor image may be its poor community relations record. Across five different types of government line agencies, the Afrobarometer asks people whether, based on their experience, they found it easy or difficult to obtain public services from that agency.

In 2006 , just $40 \%$ of all respondents said they found it "easy" or "very easy" to "get help from the police when they needed it" and $49 \%$ said it was difficult (with 19\% of these saying it was "very difficult"). These are easily the worst results of all the services asked about in the survey (Figure 6).

Eighty-three percent of those who say it is "very easy" to get help also say they trust the police, compared to just $35 \%$ of those who find it "very difficult." ${ }^{3}$ Even more disturbing, given the substantial resources poured into the transformation, training and extension of the SAPS over the past few years, these low levels of user satisfaction are unchanged from those measured four years ago.

In contrast to the racial patterns in ranking crime as a priority issue, white (41\%) and Indian (50\%) respondents are slightly more likely to report 


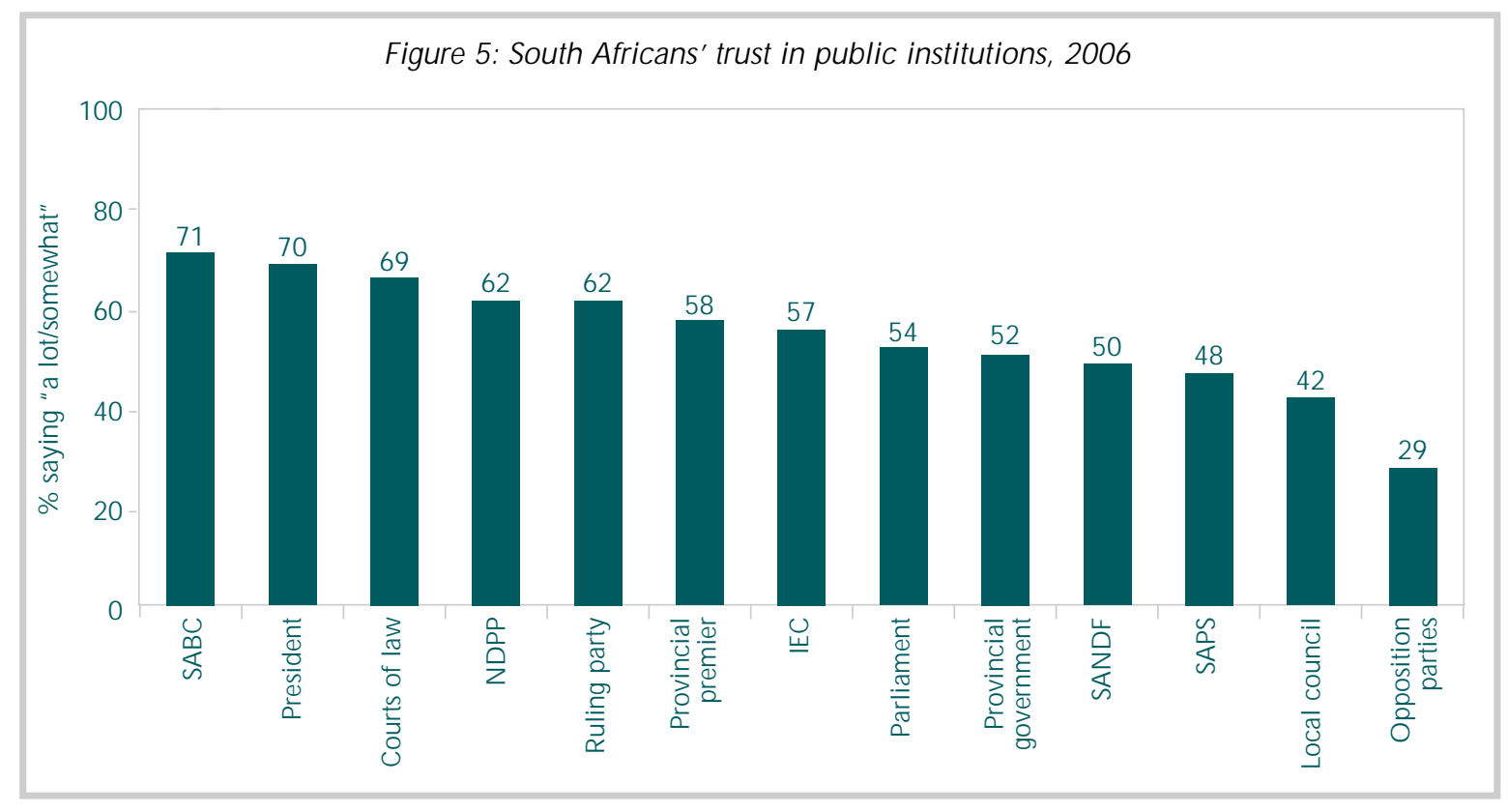

positive experiences when getting help from the police than black $(39 \%)$ or Coloured $(37 \%)$ South Africans. But the most important differences are along provincial lines. The SAPS in the Free State $(74 \%)$ and the Western Cape $(62 \%)$ are rated as the most user-friendly, while police in KwaZulu-N atal $(37 \%)$, N orthern Cape $(37 \%)$ and Gauteng (33\%) get the lowest ratings.

Another reason for the low levels of trust in the police - beyond the current level of crime - may be the fact that almost half of all South Africans (48\%) think that "all" or "most" police officials are involved in corruption (Figure 7). These figures are much higher than for other parts of the criminal justice system: just $22 \%$ believe that there are high rates of corruption among judges and magistrates. Moreover, they are the highest recorded rates across ten different offices or types of public servants.

In contrast to the improving trends in public perceptions of crime, citizen views of corruption in the police (and other government institutions) are becoming worse. While the Afrobarometer has a shorter time series of data about the police on this question, the high levels of public cynicism in elected officials evidenced in the late 1990s fell by approximately one half in 2002 and 2004. Yet even at that point, levels of perceived police corruption were about one third higher than for elected
Figure 6: Ease of access to public services, 2006

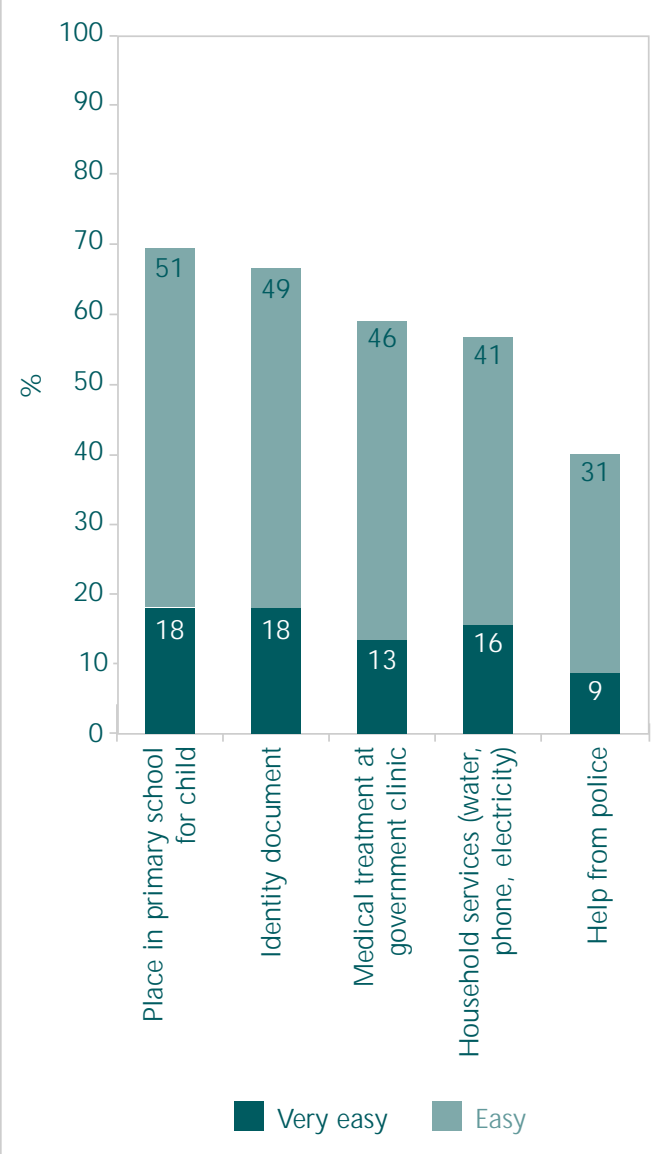


officials. From that point, they increased sharply in 2006, as did perceived corruption in local government.

Perceptions of corruption are far more prevalent than citizens' actual experiences with corrupt police. While $48 \%$ of respondents felt most police were involved in corruption, only $10 \%$ said they had to pay some form of a bribe in the past year in order to "avoid a problem with the police" (like a fine or arrest). However, this should not be seen as a reason to dismiss perceptions as totally subjective and unreliable, or to chalk them up to biased news media reporting, for two reasons:

- The survey question only asked people about their experience in the past year. If a different $9 \%$ were forced to pay a bribe each year, the perceptions measured this year might easily consist of people who have been victimised by the police at some point over the past five years.

- Perceptions of police corruption do not have to stem from direct personal experience to have some basis in reality. O ne act of extortion can easily have far broader consequences once the bribe payer returns home and tells their family and friends about it; the same tale is frequently passed on to someone else. Moreover, it takes just one or two cases of high-level official fraud reported in the media to establish widespread perceptions of corruption.
In fact, asking whether perceptions are based on reality is probably the wrong question. In the realm of politics, perceptions of corruption, even if completely distorted, become a reality in and of themselves that, among other things, erode popular trust in the police. For example, $62 \%$ of people who see no police corruption say they trust the police - compared to only $23 \%$ of those who see high levels of corruption. ${ }^{4}$

But perhaps of most importance is that comparing perceptions and actual experience begs the far more fundamental question of why such a shockingly high number - one in ten adult South Africans, or $10 \%$ - say they were asked for a bribe by the police in the past 12 months (Figure 8). Consistent with the police's dismal rating in user satisfaction, those who encounter police officials are more likely to face demands for extortion than any of the other public services we asked about.

As with the user-friendliness of the police, there were enormous provincial differences in reported experiences of being asked to pay a bribe by the police, far larger than any racial or rural-urban variations. While no respondents in the Free State, and only $2 \%$ of people from the Northern Cape reported being asked for a bribe, the figures were as high as $13 \%$ in KwaZulu-Natal, $17 \%$ in Gauteng, and $20 \%$ in Limpopo (Figure 9).

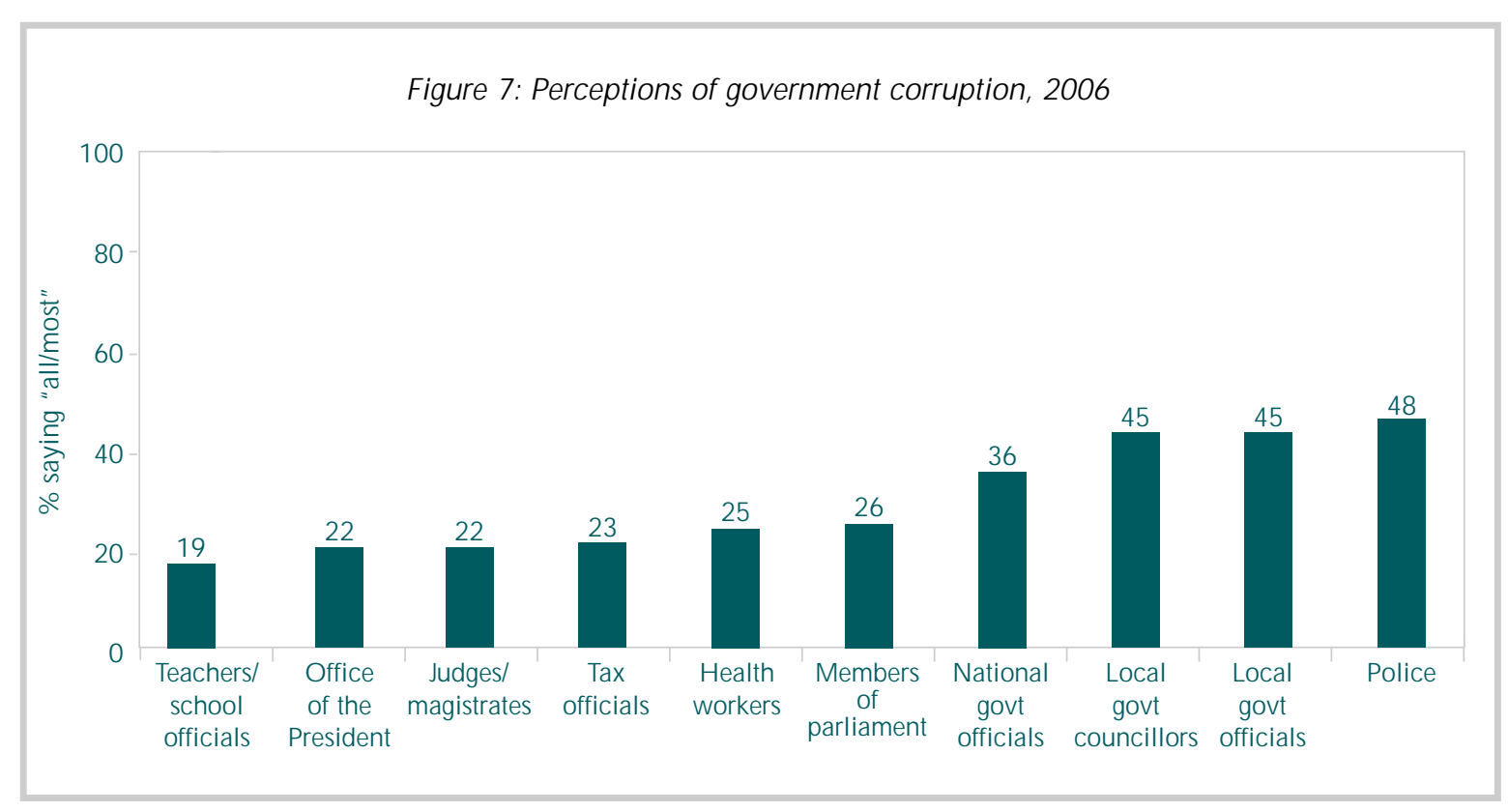


U Itimately, with this data, it is possible to build an effective explanation of why people do or don't trust the South African police. Testing all the

Figure 8: Services for which people were asked to pay bribes by public officials, 2006

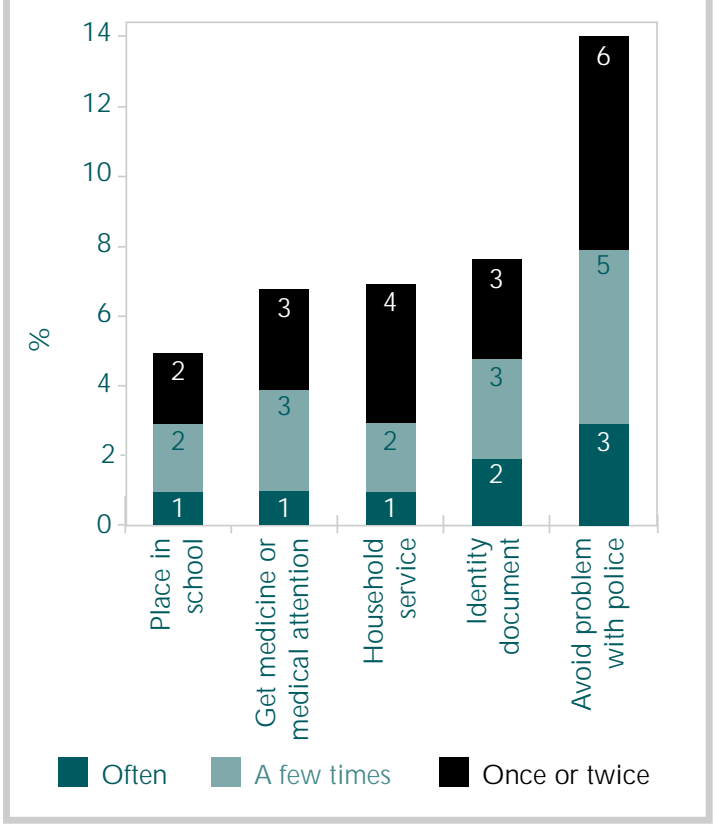

variables reviewed in this paper, it emerges that perceptions of corruption are the most important, and negative, determinant of trust, followed by public approval of government's performance in handling crime, the user-friendliness of the police, and the perception that people are safer today than a few years ago.

Importantly, once these variables are taken into consideration, people who were personally asked to pay a bribe by the police, or who were personally touched by crime, are not any more or less likely to trust the police. ${ }^{5}$

\section{Impact of perceptions on the new democracy}

Do the attitudes reviewed in this article have any larger significance for the country's new democratic system? While a final answer awaits a more complex analysis of these opinions in the broader context of other values, knowledge and evaluations, initial tests, using only the data reviewed here, confirms the general thrust of the first complete analysis of the dynamics of public opinion in Africa. ${ }^{6}$ That is, views of crime and policing do not make much of an impact on South

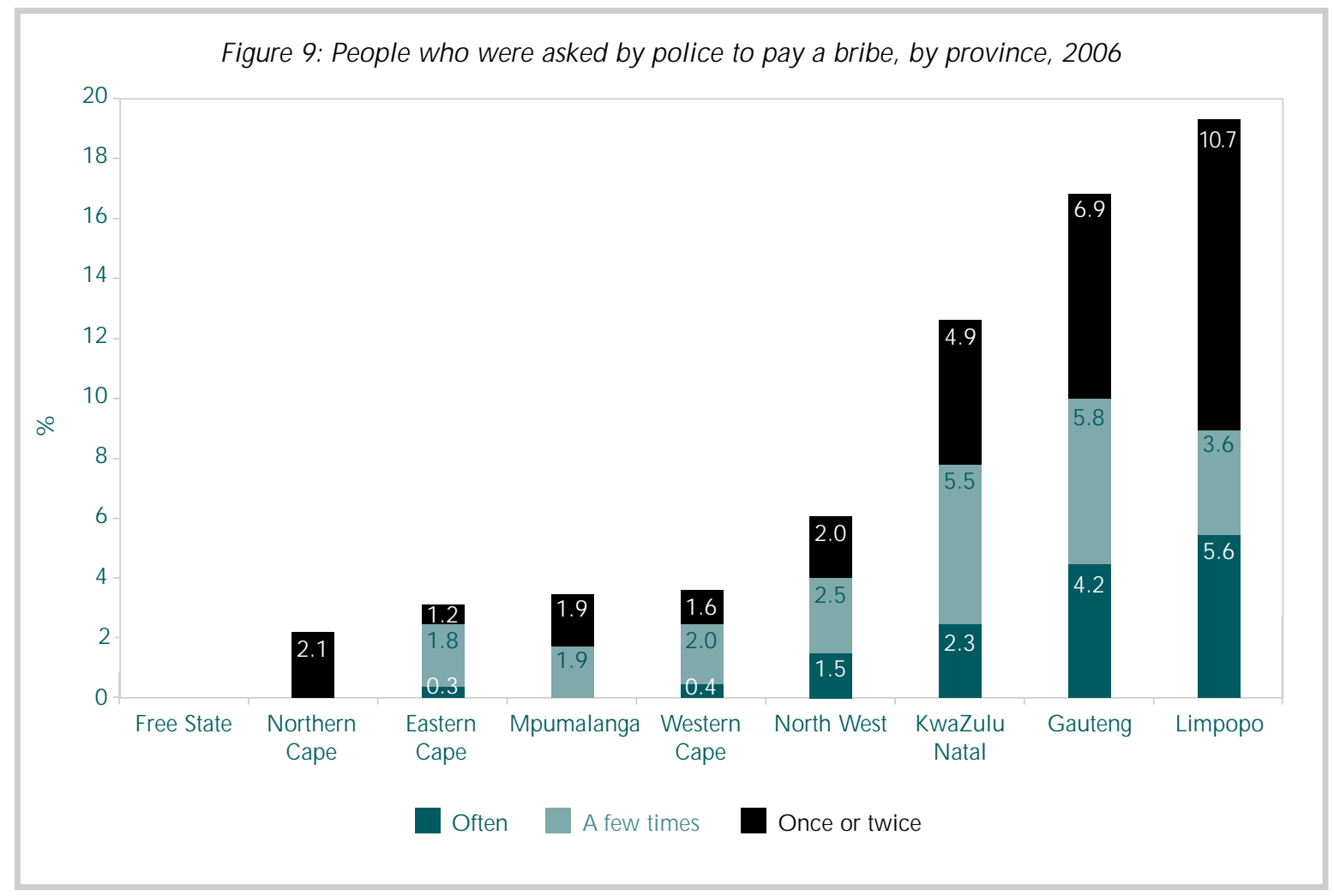


Africans' support for democracy, or the extent to which they reject non-democratic alternatives.

There are, however, important links between a specific set of views of crime and policing, and popular satisfaction with democracy as well as popular perceptions of the consolidation of democracy. In January and February of 2006, 63\% of South Africans said they were "fairly" or "very satisfied" with "the way democracy works in South Africa," and $68 \%$ felt that it was "likely" or "very likely" that South Africa would remain a democratic country."

Further analysis confirms that South Africans are less likely to be satisfied with democracy, or to say that the country would remain a democracy, if they had been victims of a physical assault in the previous 12 months. They are more likely to be satisfied, and confident in the future of democracy, if they feel people are safer now than in the past, approve of government efforts to combat crime, find it easy to deal with the police, and express trust in the police. ${ }^{7}$

\section{Endnotes}

1 Mattes is professor in Political Studies, and director of the Centre for Social Science Research at the University of Cape Town. He is also a co-founder of, and senior advisor to, the Afrobarometer.

2 These comparisons can only be illustrative since the Afrobarometer draws a representative sample of all adult citizens, not the entire population. Thus, to reach this figure, I calculated the actual population figure represented by $19 \%$ of all adult South Africans and applied this against the total population.

3 The rank order correlation of the reported ease of working with the police and trust in the police is (Tau B) $.198, p=.000$.

4 Perceptions of corruption and trust in the police are correlated at (Tau B) -.238, p=.000. In contrast, personal victimisation at the hands of the police has no effect on trust (Tau $B=-.034, p .=.117$ ).

5 A model consisting of just these four variables explains $17 \%$ of the variance in trust in the police. The standardised regression coefficients are: perceptions of police corruption (-.227); government performance handling crime (.161); user friendliness of police (.159); and increased safety from crime and violence (.107).

6 M Bratton, R Mattes and E Gyimah-Boadi, Public $O$ pinion, Democracy and Market Reform in Africa, Cambridge, Cambridge U niversity Press, 2005.

7 The model consists of five variables. It explains 16\% of the variance in satisfaction with democracy. The standardised regression coefficients are: increased safety from crime and violence (.211), trust in the police (.116), user friendliness of the police (.115), government performance handling crime (.110) and victim of a physical attack (-.099). The same model also explains $9 \%$ of the variance in popular confidence in the future of democracy. The standardised regression coefficients are: increased safety from crime and violence (.114), government performance handling crime (.112), trust in the police (.101), user friendliness of the police .100) and victim of a physical attach $(-.079)$. 